\title{
Alveolar echinococcosis
}

INSERM

\section{Source}

INSERM. (1999). Orphanet: an online rare disease and orphan drug data base. Alveolar echinococcosis. ORPHA:284

Alveolar echinococcosis (AE) is a rare parasitic disorder that occurs after ing estion of eggs of Echinococcus multilocularis. AE is characterized by an initial asymptomatic incubation period of many years followed by a chronic course where the clinical manifestations include epigastric pain and jaundice. 